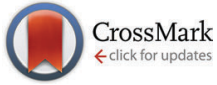

Cite this: Phys. Chem. Chem. Phys., 2014, 16, 20598

\title{
Singlet oxygen generation in porphyrin-doped polymeric surface coating enables antimicrobial effects on Staphylococcus aureus
}

\author{
Ariane Felgenträger, ${ }^{a}{ }^{a}$ Tim Maisch, $^{a}$ Andreas Späth, ${ }^{b}$ Josef A. Schröder $^{c}$ and \\ Wolfgang Bäumler ${ }^{a}$
}

\begin{abstract}
Surfaces can be coated with photosensitizer molecules, which generate singlet oxygen $\left({ }^{1} \mathrm{O}_{2}\right)$ when the surface is exposed to light. ${ }^{1} \mathrm{O}_{2}$ may diffuse from the coating and has the potential to kill microorganisms present on the surface. In the present study a derivative of the meso-tetraphenylporphyrin (TPP) was immobilized onto polyurethane (PU) after being sprayed and polymerized as a thin layer onto polymethylmethacrylate (PMMA). PU is gas permeable and thus a sufficient amount of oxygen reaches the photosensitizer in this coating. The surface generation of ${ }^{1} \mathrm{O}_{2}$ and its diffusion were investigated by detecting its luminescence at $1270 \mathrm{~nm}$ and a tri-iodide assay. Antimicrobial photodynamic surface effects were tested on Staphylococcus aureus. The spectrally resolved detection of ${ }^{1} \mathrm{O}_{2}$ luminescence yielded a clear peak at $1275 \mathrm{~nm}$. The time-resolved luminescence showed multi-exponential decay, revealing rise and decay times in the range of $5-2 \times 10^{2} \mu \mathrm{s}$. The photodynamic inactivation of S. aureus was monitored at different photosensitizer concentrations and radiant exposures of light. A photodynamic killing of $>99.9 \%$ ( $>3 \log _{10}$-steps) was achieved within an irradiation time of $30 \mathrm{~min}$. The photodynamic killing on the bioactive surface confirmed the antimicrobial effect of ${ }^{1} \mathrm{O}_{2}$ that was generated in the PU-coating and

reached the bacteria by diffusion.
\end{abstract}

Received 3rd June 2014,
Accepted 7th August 2014
DOI: $10.1039 /$ c4cp02439g

www.rsc.org/pccp

\section{Introduction}

Microorganisms are frequently distributed via contaminated surfaces, which are in alternating contact with different individuals. ${ }^{1}$ Persistence of clinically relevant bacteria on dry inanimate surfaces can remain up to several years. ${ }^{2}$ It is of great importance to interrupt this transmission pathway by a self-disinfecting effect of surfaces. So far, different approaches and biomaterials were investigated that were summarized by Page et al. and Campoccia et $a l^{3,4}$ Recently, silver nanoparticles were used as monolayer coatings, which were firmly anchored on a surface avoiding the release towards microorganisms. ${ }^{5}$ To achieve pathogen killing, the method of photodynamic inactivation (PDI) of microorganisms can be applied. In PDI, a dye molecule (photosensitizer, PS) is excited by light. The energy is transferred to other molecules like oxygen resulting in the formation of reactive oxygen species, $\operatorname{ROS}^{6}$ (e.g. singlet oxygen, ${ }^{1} \mathrm{O}_{2}$ ), that can cause cell death. ${ }^{7-9}$ Using this

\footnotetext{
${ }^{a}$ Department of Dermatology, Regensburg University Hospital,

Franz-Josef-Strauss-Allee 11, 93053 Regensburg, Germany.

E-mail: ariane.felgentraeger@klinik.uni-regensburg.de

${ }^{b}$ Department of Organic Chemistry, University of Regensburg,

Universitätsstrasse 31, 93053 Regensburg, Germany

${ }^{c}$ Department of Pathology/Central EM-Lab, Regensburg University Hospital,

Franz-Josef-Strauss-Allee 11, 93053 Regensburg, Germany
}

principle, surfaces can be coated with thin polymer layers containing PSs which generate ROS upon light irradiation. After being generated, ROS should diffuse out of the thin coating, reach the microorganisms present on the surface, and kill them via oxidation processes (Fig. 1).

In contrast to the well-known PDI, the PS molecules are not attached to the microorganisms but are located in the coating. Thus, the diffusion of ROS is required to accomplish the killing of microorganisms on such self-disinfecting surfaces. Among the $\operatorname{ROS}{ }^{1} \mathrm{O}_{2}$ should play a major role due to its chemical and physical features. Being a neutral molecule, ${ }^{1} \mathrm{O}_{2}$ is - contrary to other ROS - assumed to show normal diffusion in air, and the lifetime of ${ }^{1} \mathrm{O}_{2}$ is, besides its spontaneous decay, limited by collisions and reactions with air molecules.

In 1986 Dahl et al. already described a method to investigate the toxicity of diffusing ${ }^{1} \mathrm{O}_{2}$ using spatial separation of PS and bacteria. ${ }^{10}$ The half-life of ${ }^{1} \mathrm{O}_{2}$ was determined by changing the distance between the site of ${ }^{1} \mathrm{O}_{2}$ generation and the position of the bacteria by measuring the bacteria killing of ${ }^{1} \mathrm{O}_{2}$. These experiments yielded a half-life for ${ }^{1} \mathrm{O}_{2}$ of $24 \pm 6 \mathrm{~ms}$ and confirmed findings of the ${ }^{1} \mathrm{O}_{2}$ decay time in the range of milliseconds 35-86 ms detected in water-saturated air at $5{ }^{\circ} \mathrm{C}$ with $1 \mathrm{~atm}$ pressure. ${ }^{11}$ The generated ${ }^{1} \mathrm{O}_{2}$ molecules reached a pathogen by diffusion, and the diffusion length of biologically 
(A)

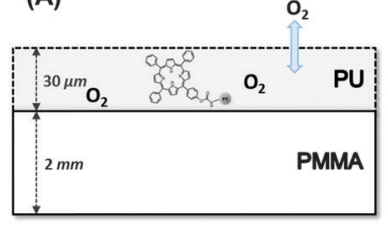

(C)

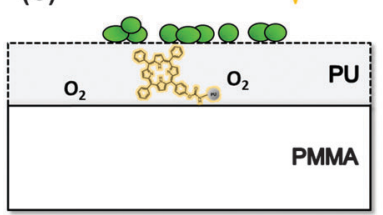

(B)
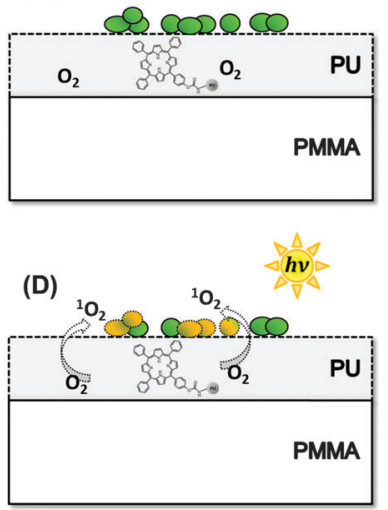

Fig. 1 Scheme of the photosensitisation process and microorganism deactivation on the surface; (A) basic PMMA polymer surface coated with PU (thickness $\approx 30 \mu \mathrm{m}$ ); PU enables $\mathrm{O}_{2}$-gas diffusion; (B) microorganism accumulation and contamination of the surface; (C) PS excitation upon irradiation; (D) ${ }^{1} \mathrm{O}_{2}$ generation by energy transfer from excited PS to $\mathrm{O}_{2}$; microorganisms in the diffusion radius of ${ }^{1} \mathrm{O}_{2}$ are oxidised (photokilling process).

relevant action was limited by the lifetime of ${ }^{1} \mathrm{O}_{2}$. These studies provided insight into an interesting field of antimicrobial PDI, where PS and pathogens were separated during the PDI process.

PDI of bacteria without direct contact between PS and microorganisms offers many fields of application. Antibacterial surfaces which work with the PDI principle are of great interest due to their preventive character for infections. ${ }^{12-14}$ Such surfaces may help to reduce the transmission of pathogens like multiresistant microorganisms, which is a great issue in hospital hygiene. ${ }^{1}$ Since the photodynamic process of such surfaces does not necessarily lead to PS consumption, self-disinfecting coatings could offer a long-term and constant prevention of microorganism settlement and growth on any surface. ${ }^{15}$

It was already shown that polymerisation of a PS prevents oligomerisation and thus self-quenching of ${ }^{1} \mathrm{O}_{2}$ that improved both ${ }^{1} \mathrm{O}_{2}$ formation and photostability of the PS. ${ }^{16}$ We present herein a new polymeric surface that contains the functionalized porphyrin TPP (Fig. 2) using the polymerization technique of isocyanate/polyol to polyurethane. TPP shows a sufficient quantum yield for ${ }^{1} \mathrm{O}_{2}$ generation of 0.62 in $\mathrm{CCl}_{4}$ and 0.68 in toluene, respectively. ${ }^{17}$ Characterizing TPP-OH linked in the PU polymer required the detection of the ${ }^{1} \mathrm{O}_{2}$ generation that is performed directly via its luminescence at $1270 \mathrm{~nm}$.

The decay time of ${ }^{1} \mathrm{O}_{2}$ in air was estimated to be in the range of milliseconds. ${ }^{10,11}$ Due to the very long lifetime of ${ }^{1} \mathrm{O}_{2}$, indirect methods like the formation of tri-iodide ${ }^{18}$ or a phototoxic assay with microorganisms are suitable to detect ${ }^{1} \mathrm{O}_{2}$ that escaped the surface coating by diffusion. ${ }^{1} \mathrm{O}_{2}$ molecules, which decayed inside the polymeric surface coating, can be detected by its luminescence. Additionally, the structure of the PU surface was investigated using transmission electron microscopy.

Furthermore, any PS leaking into surrounding $\mathrm{H}_{2} \mathrm{O}$ was proved in a defined time range before testing the potential antibacterial properties against Staphylococcus aureus, which was placed as a $\mathrm{H}_{2} \mathrm{O}$-based bacterial suspension on the surface.
(A)<smiles></smiles>

(B)

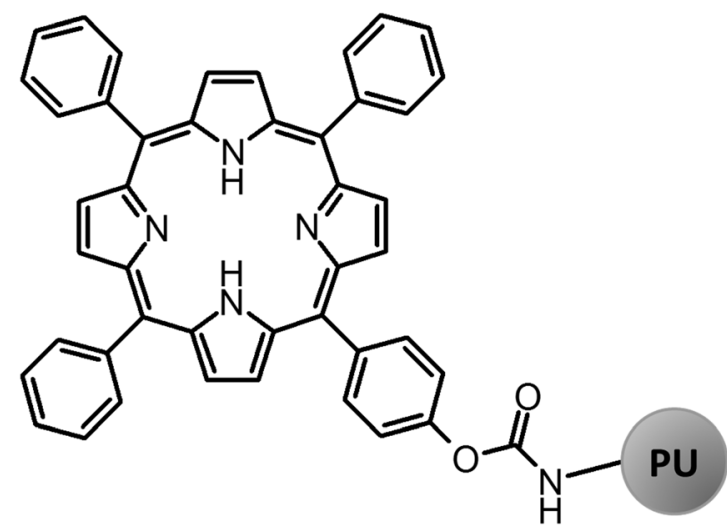

Fig. 2 Chemical structure formula of (A) $\mathrm{TPP}-\mathrm{OH}$ and (B) TPP-OH polymerized in PU.

The photodynamic killing efficacy was investigated for different PS concentration in PU and different irradiation times.

\section{Material and methods}

\section{Chemicals}

Potassium iodide (KI) was received from Sigma Aldrich (Steinheim, Germany). The 5-(4-Hydroxyphenyl)-10,15,20-triphenylporphyrin (TPP-OH, Fig. 2) was synthesized in cooperation with the Institute of Organic Chemistry, University of Regensburg, based on the molecular structure of the meso-=tetraphenylporphyrin (TPP). An additional hydroxyl group (-OH) was added to the ring system of TPP, improving the literature-known procedure. ${ }^{19}$ Therefore, a solution of 4-hydroxybenzaldehyde $(8.79 \mathrm{~g} ; 71.9 \mathrm{mmol})$ and benzaldehyde $(24.0 \mathrm{~mL}, 24.7 \mathrm{mmol})$ in propionic acid $(700 \mathrm{~mL})$ was heated to nearly reflux. A solution of pyrrole $(18.0 \mathrm{~mL}$, $26.0 \mathrm{mmol})$ in propionic acid $(20 \mathrm{~mL})$ was added dropwise to the yellow solution. The reaction mixture was stirred under reflux for $1.5 \mathrm{~h}$. After cooling, propionic acid was evaporated in vacuo. The dark residue was filtered through a silica column with $\mathrm{CH}_{2} \mathrm{Cl}_{2}\left(\mathrm{DCM}, R_{\mathrm{f}}=0.2\right)$ as an eluent. The solvent was again evaporated under reduced pressure. Next, the dark solid was 
recrystallized from $\mathrm{EtOH}$, followed by another column purification with $\mathrm{CH}_{2} \mathrm{Cl}_{2}$ as an eluent, to yield a violet solid $(1.8 \mathrm{~g}, 29.0 \mathrm{mmol}$, $4 \%$ relating to 4-hydroxybenzaldehyde).

$M=630.74 \mathrm{~g} \mathrm{~mol}^{-1} ;{ }^{1} \mathrm{H}-\mathrm{NMR}\left(400 \mathrm{MHz} ; \mathrm{CDCl}_{3}\right): \delta[\mathrm{ppm}]=$ $8.88(\mathrm{~d}, J=4.8 \mathrm{~Hz}, 2 \mathrm{H}) ; 8.85(\mathrm{~d}, J=6.2 \mathrm{~Hz}, 6 \mathrm{H}) 8.22(\mathrm{dd}, J=$ $1.6 \mathrm{~Hz}, J=7.8 \mathrm{~Hz}, 6 \mathrm{H}), 8.08(\mathrm{~m}, 2 \mathrm{H}), 7.76(\mathrm{~m}, 9 \mathrm{H}), 7.20(\mathrm{~d}, J=$ $8.4 \mathrm{~Hz}, 2 \mathrm{H}) ;-{ }^{13} \mathrm{C}-\mathrm{NMR}\left(75 \mathrm{MHz}, \mathrm{CDCl}_{3}\right): \delta[\mathrm{ppm}]=155.4(1 \mathrm{C})$, 142.2 (3C), 135.7 (2C), 134.6 (6C), 131.1 (1C), 127.7 (2C), 126.7 (9C), 120.1 (8C), 113.7 (8C); - MS (ES-MS): $m / z(\%)=631.3$ $\left(100, \mathrm{MH}^{+}\right)$;

\section{PMMA polymer plates coated with polyurethane ${ }^{20}$ containing TPP-OH}

The TPP porphyrin derivative TPP-OH was dissolved in the liquid PU material (PUR A Überzugslack 2K, Warnecke \& Boehm, Germany) which is a mix of aliphatic, linear and branched polyvalent alcohols with a density of $0.98 \mathrm{~kg} \mathrm{~L}^{-1}$. A mix of pure PU and a hardener (57.00.007, Warnecke \& Boehm, Germany) in the ratio of 5:1 was appropriate for the polymerisation procedure. The functionalized TPP-OH polymerized via linking of hydroxyl groups $(-\mathrm{OH})$ with isocyanates $(-\mathrm{CNO})$ into polyurethane. ${ }^{20}$ The resulting mix was sprayed with a professional airbrush system (Warnecke \& Boehm, Germany) onto a poly-methylmethacrylate (PMMA) polymer plate (thickness of $2 \mathrm{~mm}$ ) using the spraying pistol SATA jet 1000B RP (parameters: spraying entrance pressure of 2.5 bar, nozzle size of $1.5 \mathrm{~mm}$, cross coat 1.5 , spraying distance of $20 \mathrm{~cm}$ ). The samples were allowed to crosslink for one hour at a temperature of $20{ }^{\circ} \mathrm{C}$. Finally, the thickness of the PU-coating had optimal mechanical properties at a thickness of $\approx 30 \mu \mathrm{m}$, which is an empirical value for avoiding cracks in the coating, than might occur for thinner coatings $(<25 \mu \mathrm{m})$ or thicker coatings $(>75 \mu \mathrm{m})$. Furthermore, the $\mathrm{O}_{2}$ gas diffusion is faster for thinner layers, which is important for continuous ${ }^{1} \mathrm{O}_{2}$ generation. PMMA has the best absorption properties to be used as a basic polymer material for adding a PU-coating, because its first absorption band is below $380 \mathrm{~nm}$ and therefore an interaction with visible light is avoided. The PU-polymer surfaces can be used as coatings due to a simple application technique.

In order to produce the sandwich-samples, after the spraying of PU onto PMMA, a second PMMA-plate was immediately added to the surface before the drying process of the sample.

\section{Absorption spectroscopy}

Absorption spectra were recorded at room temperature using a spectrophotometer (DU640, Beckman Instruments $\mathrm{GmbH}$, Munich, Germany) and the absorption is given in percentage values.

\section{Photostability}

TPP-OH linked in PU was irradiated using the Waldmann PIB 3000 (emission $\lambda_{\text {em }}>400 \mathrm{~nm}$, Herbert Waldmann GmbH \& Co. KG, Germany) as a broadband light source using a power of $50 \mathrm{~mW} \mathrm{~cm}^{-2}$ at the level of the samples. Samples were irradiated for 5,30 , and $60 \mathrm{~min}$, resulting in a light dose of 15,90 , and $180 \mathrm{~J} \mathrm{~cm}^{-2}$.
After irradiation, absorption spectroscopy was carried out using pure PU coated onto PMMA as blank. The resulting spectra were compared to the spectra of the non-irradiated samples.

\section{Phototoxicity}

In this study the Gram(+) Staphylococcus aureus (ATCC 25923) was grown aerobically at $37{ }^{\circ} \mathrm{C}$ for $16 \mathrm{~h}$ overnight in $5 \mathrm{~mL}$ Mueller-Hinton ( $\mathrm{MH}$ ) broth (Gibco Life Technologies $\mathrm{GmbH}$, Eggenstein, Germany). When the culture reached the stationary phase of growth the bacteria were harvested by centrifugation (200 g, $10 \mathrm{~min}$ ), washed with phosphate-buffered saline (PBS; Biochrom, Berlin, Germany) at $\mathrm{pH} 7.4$, and suspended in PBS

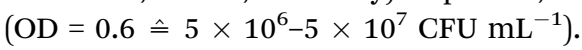

$50 \mu \mathrm{L}$ of a $S$. aureus suspension was dropped on the PU-surface with and without TPP-OH and dried for $1.5 \mathrm{~h}$ under a laminar flow. Each drop has a radius of about $0.5 \mathrm{~cm}$ and therefore covered an area of $A \approx 0.8 \mathrm{~cm}^{2}$. The cell number per area was in the range of $6.3 \times 10^{6}-6.3 \times 10^{7} \mathrm{CFU} \mathrm{cm}^{-2}$.

Samples were irradiated using the Waldmann PIB 3000 at a maximal light intensity of $50 \mathrm{~mW} \mathrm{~cm} \mathrm{~cm}^{-2}$ at the level of the irradiated samples. Two different irradiation times (10 and $30 \mathrm{~min}$ ) with PS concentrations of $0,1 \times 10^{-4} \mathrm{M}$, and $2 \times 10^{-4} \mathrm{M}$ were used.

After irradiation, the bacteria were swapped with a sterile cotton bud and were diluted in $1 \mathrm{~mL} \mathrm{MH-broth.} \mathrm{Bacteria} \mathrm{were}$ serially 10-fold diluted in MH-broth and plated on MH-Agar using the Miles, Misra \& Irwin method. ${ }^{21}$ After growing at $37{ }^{\circ} \mathrm{C}$ for $24 \mathrm{~h}$ the colony forming units (CFU) were counted. The results are shown as medians, including the $25 \%$ and $75 \%$ percentiles and the maximal and minimal value, calculated from the values of at least four independent experiments, each performed in triplicate. The results are presented in a box-andwhisker plot. To calculate the killing efficacy in $\log _{10}$-steps for each condition (no imbedded PS, $10^{-4} \mathrm{M}, 2 \times 10^{-4} \mathrm{M}$ ) the respective dark control was used as reference. An efficacy of bacteria killing of $99.9 \%$ ( $3 \log _{10}$-steps) is considered as biologically relevant antimicrobial activity according to the guidelines of hand hygiene. ${ }^{22}$

\section{Singlet oxygen luminescence detection by direct spectroscopic methods}

The PU surfaces with and without TPP-OH were excited using a tunable laser system (EKSPLA, Lithuania) at $\lambda=420 \mathrm{~nm}$, laser power output $P=360 \mathrm{~mW}$, repetition rate of $f=1 \mathrm{kHz}$, and 10000 laser pulses ( $=10 \mathrm{~s}$ irradiation time) with a pulse duration of 4-7 ns. With the given parameters an energy of $E_{\mathrm{p}}=3.6 \times 10^{-4} \mathrm{~J}$ per pulse was applied.

Direct detection of the weak ${ }^{1} \mathrm{O}_{2}$ luminescence as described in $^{23,24}$ was done by time-resolved measurements using an interference filter with a maximal transmission at $1270 \mathrm{~nm}$ and a spectral width of FWHM = $30 \mathrm{~nm}$ using a liquid nitrogen cooled infraredsensitive photomultiplier tube (PMT, R5509-42, Hamamatsu Photonics Deutschland GmbH, Herrsching, Germany). To achieve spectral resolution, the luminescence was measured at different wavelengths using different interference filters in the range of 1100-1400 nm (FWHM $\approx 10 \mathrm{~nm}$ ). The resulting values were fitted with Lorentzshaped function yielding a maximum at $\lambda=1275 \mathrm{~nm}$. 
Considering no energy back-transfer from ${ }^{1} \mathrm{O}_{2}$ to the PS, the luminescence intensity is then given by equation

$$
I(t)=\frac{C}{t_{\mathrm{R}}^{-1}-t_{\mathrm{D}}^{-1}}\left[\exp \left(-\frac{t}{t_{\mathrm{D}}}\right)-\exp \left(-\frac{t}{t_{\mathrm{R}}}\right)\right]
$$

where $C=\left[\mathrm{T}_{1}\right]_{t=0} k_{\mathrm{T}_{1} \Delta}\left[\mathrm{O}_{2}\right]$ was used to fit the ${ }^{1} \mathrm{O}_{2}$ luminescence signal, and $t_{\mathrm{R}}$ and $t_{\mathrm{D}}$ are the rise and decay times that are assigned to either the decay time of the excited triplet state of the PS $\tau_{\mathrm{T}}$ or the decay time of ${ }^{1} \mathrm{O}_{2} \tau_{\Delta}$. The meaning of the rise and decay time can change depending on the oxygen concentration. ${ }^{24}$ For the optimisation of the fit, the LevenbergMarquardt-algorithm of Mathematica (V. 5.2, Wolfram Research, Champaign, USA) was used. The exact mathematical descriptions and deviation of the formula for the luminescence intensity using the rate and rate constants are reported elsewhere. ${ }^{24}$

\section{Indirect detection of singlet oxygen with potassium iodide (KI)} on the surface

Indirect detection of ${ }^{1} \mathrm{O}_{2}$ was performed with potassium iodide (KI). This substance reacts with ${ }^{1} \mathrm{O}_{2}$ via the following mechanism, which was described by Mosinger et al. ${ }^{18,25}$

$$
\begin{aligned}
{ }^{1} \mathrm{O}_{2}+\mathrm{I}^{-}+\mathrm{H}_{2} \mathrm{O} & \stackrel{-\mathrm{OH}^{-}}{\longrightarrow} \mathrm{IOOH} \stackrel{+\mathrm{I}^{-}}{\longrightarrow} \mathrm{HOOI}_{2}^{-} \rightarrow \mathrm{I}_{2}+\mathrm{HO}_{2}^{-} \\
& \stackrel{+\mathrm{I}^{-},+\mathrm{H}_{2} \mathrm{O}}{\longrightarrow} \mathrm{I}_{3}^{-}+\mathrm{H}_{2} \mathrm{O}_{2}+\mathrm{OH}^{-}
\end{aligned}
$$

In water the reaction of ${ }^{1} \mathrm{O}_{2}$ and the iodine anion results in the formation of tri-iodide $\mathrm{I}_{3}{ }^{-}$. During this process hydrogen peroxide, $\mathrm{H}_{2} \mathrm{O}_{2}$, is generated which can react further with $\mathrm{I}^{-}$.

An overall volume of $3 \mathrm{~mL} \mathrm{KI}$ with a concentration of $0.12 \mathrm{M}$ in $\mathrm{H}_{2} \mathrm{O}$ was filled in a glass surrounding a polymer plate. In the case of the PMMA polymer plates with PU-coating the photoactive side was turned upside. The samples were irradiated for $0,5,10,15$, and $30 \mathrm{~min}$ and after each time point $2 \mathrm{~mL}$ of the solution was spectrally recorded, in order to monitor the formation of tri-iodide $\mathrm{I}_{3}{ }^{-}$at $287 \mathrm{~nm}$ and $350.5 \mathrm{~nm}$. After absorption spectroscopy the solution was filled back into the glass for further irradiation and monitoring steps.

\section{Transmission electron microscopy}

The PU surfaces were investigated by transmission electron microscopy (TEM, LEO 912AB, Zeiss, Oberkochen, Germany) at $100 \mathrm{kV}$ in cooperation with the Central EM Lab at the University Hospital Regensburg. Small samples of PMMA polymer plates coated with a PU layer (not light treated = control) were cut into ultrathin sections (80 $\mathrm{nm})$ using an ultramicrotome and mounted on TEM-microscopy grids. The sections were examined in the TEM without additional heavy metal contrast enhancement. The documentation was performed using a CCD-camera with the OSIS-Software iTEM (Olympus Soft Imaging Solutions, Münster, Germany).

\section{Results and discussion}

First, the properties of the PU-coating were investigated regarding light microscopic properties, absorption and photostability of the embedded PS. Light absorption measurements of TPP$\mathrm{OH}$ immobilized on PU should elucidate a possible porphyrin aggregation after polymerisation, which is known to reduce the ability to generate ${ }^{1} \mathrm{O}_{2} \cdot{ }^{26}$ The photostability of the porphyrin in the surface was tested under the same conditions as those applied for the phototoxicity experiments. A possible leaking effect of the immobilized PS out of the coating was tested because such PS molecules could reach the bacteria on the surface leading to cell killing. This could overlap the expected cell killing by ${ }^{1} \mathrm{O}_{2}$ that diffused from the coating surface to bacteria and hence would yield a false positive result regarding killing of microorganisms. Thus, the PU coating with embedded TPP-OH was placed in $\mathrm{H}_{2} \mathrm{O}$ for a certain time span and the absorption of the supernatant was monitored to ensure that no unbound PS molecules reach the pathogens.

\section{Microscopic properties of the PU-coating}

The polymeric surface was developed using PMMA as the basic polymer. A coating was applied via an airbrush technique using PU varnish with and without the respective PS TPP-OH. After the polymerization process the thickness of the coating was in the range of several tens of micrometres.

Transmission electron microscopy (TEM) was performed to understand the microscopic composition, such as roughness, constancy of thickness or the properties of the contact area of the PU-coating (containing TPP-OH) with the PMMA material. Fig. 3A shows a surface probe with a 1000-fold magnification. Because the samples contained no contrasting heavy atoms, TEM imaging revealed a homogenous texture of the PU- and PMMA-layer. The PMMA part showed a periodical-like structure that might be caused by the cutting of samples with a microtome. The cutting was performed perpendicular to the periodical-like structure. The images indicated a very tight and precise contact area between the PU-coating and PMMA with a thickness of the PU-coating of $\approx 30 \mu \mathrm{m}$. The images also showed a few round empty areas disseminated in the PU-coating (Fig. 3B) but not in PMMA. These structures were considered air bubbles, which

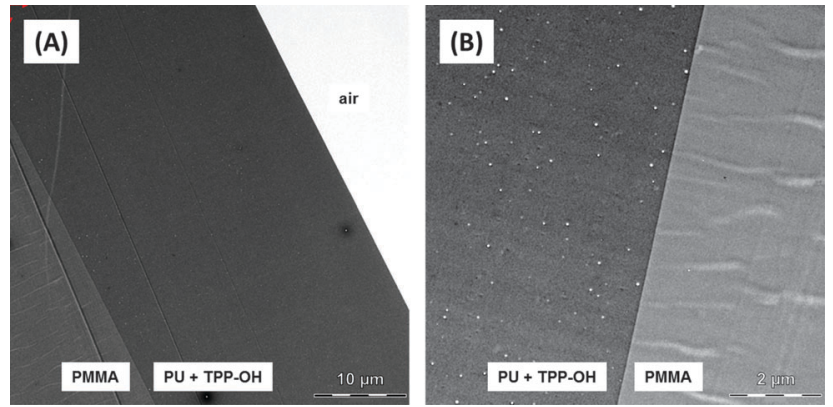

Fig. 3 TEM image of a PMMA polymeric surface with PU-coating containing $\mathrm{TPP}-\mathrm{OH}$ (concentration $10^{-4} \mathrm{M}$; thickness $\approx 30 \mu \mathrm{m}$ ); untreated with light (dark control); original TEM magnification $(A) \times 1000$; (B) $\times 5000$. 
might occur due to the airbrushing of the fluid PU-varnish onto the PMMA material. Diffusion of ${ }^{1} \mathrm{O}_{2}$ in these air bubbles might affect the decay time of ${ }^{1} \mathrm{O}_{2}$ in PU because ${ }^{1} \mathrm{O}_{2}$ decay time in the bubbles should differ from decay time in the PU material. ${ }^{10,11}$

\section{Absorption spectra of the PU-PMMA material and TPP-OH in PU}

PMMA showed different properties that are versatile for their use as a basic layer. First, PMMA is a common and cheap material and is inured to scratches or similar mechanical influences. Second, it is transparent in the visible part of the electromagnetic spectrum and the first absorption band can be detected below $380 \mathrm{~nm}$, which did not change when adding PU to its surface (Fig. 4A). Above $380 \mathrm{~nm}$, PMMA coated with PU showed a constant absorption of $8 \%$, which is considered to be an artificial value because it was based only on reflection properties.

The data of the absorption spectra of TPP-OH doped into PU were compared to data of the porphyrin TPP in solution found in the literature. Brückner et al. reported a maximum absorption coefficient of TPP in chloroform $\left(\mathrm{CHCl}_{3}\right)$ at a wavelength of $S$ (Soret) = $416 \mathrm{~nm}\left(Q_{1}=515 \mathrm{~nm}, Q_{2}=550 \mathrm{~nm}, Q_{3}=593 \mathrm{~nm}, Q_{4}=646 \mathrm{~nm}\right),{ }^{27}$ which was confirmed by Korinek et $a .^{28}$ in air-saturated acetone. The absorption spectrum of TPP-OH linked in the PU-polymer was detected by subtraction of the PU-PMMA absorption spectrum without the PS (blank). The main absorption bands of TPP-OH in the PU-polymer were detected at $S$ (Soret) $=420 \mathrm{~nm}, Q_{1}=516 \mathrm{~nm}$, $Q_{2}=551 \mathrm{~nm}, Q_{3}=592 \mathrm{~nm}, Q_{4}=647 \mathrm{~nm}$ (Fig. 4B). Therefore, the determined maxima of the absorption intensity are in good agreement with the maxima of TPP in solution. Our measurements revealed no spectral shift of the Soret band which would indicate porphyrin-porphyrin aggregation during the preparation of the PU-coating. Aggregation could result in a loss of the ability to generate ${ }^{1} \mathrm{O}_{2} \cdot{ }^{29-31}$ Nonetheless, polymerization of TPP-OH in PU can result in decreased degrees of freedom for the vibrational bands of the PS, resulting in more narrow absorption bands.

\section{Leakage of PS from the PU-coating}

The indirect detection methods for ${ }^{1} \mathrm{O}_{2}$ included the contact of the PU-surface material with $\mathrm{H}_{2} \mathrm{O}$-based suspensions of bacteria and solutions of potassium iodide in $\mathrm{H}_{2} \mathrm{O}$. Although TPP-OH is not water soluble, a potential PS leakage into these $\mathrm{H}_{2} \mathrm{O}$-based surroundings was investigated. In order to test the polymerisation strength of PS and the PU coating material, a PS release was additionally tested with $70 \% \mathrm{EtOH}$, which is a standard concentration for disinfection purposes. Therefore, the PU-coated surface was placed either in $\mathrm{H}_{2} \mathrm{O}$ for 7 days or in $70 \% \mathrm{EtOH}$ for $48 \mathrm{~h}$, keeping the samples in the dark. After the respective time span, the light absorption of the supernatant $\left(\mathrm{H}_{2} \mathrm{O}, \mathrm{EtOH}\right)$ was measured in the spectral range from $200-1000 \mathrm{~nm}$.

The embedded hydrophobic TPP-OH with a concentration of $10^{-4} \mathrm{M}$ showed no leaking into the aqueous surrounding (data not provided). By applying 70\% EtOH for $48 \mathrm{~h}$, a leakage of TPP-OH into the supernatant was detected by monitoring the characteristic TPP-OH absorption intensity peak at $420 \mathrm{~nm}$. TPP-OH molecules, which escaped from the PU-coated surface into EtOH, are most likely molecules that were not sufficiently linked to PU (un-polymerized fraction). As a consequence they were flushed out due to the long contact with EtOH. However, this leakage effect should be put into perspective. The transmission value at $420 \mathrm{~nm}$ for this experiment was $(88 \pm 2) \%$. With an absorption cross section $(\sigma)$ of $10^{-16} \mathrm{~cm}^{2}$, which is a reasonable value for porphyrins at $420 \mathrm{~nm}$, a PS concentration of $\approx 2 \mu \mathrm{M}$ in the EtOH supernatant can be estimated. When disinfecting a surface with EtOH solutions, EtOH is in contact with the surface only for a rather short time, usually several tens of seconds. Calculating with an effective disinfection and estimating a contact time of $\approx 1 \mathrm{~min}$, the 48 h-experiment equals $\approx 2880$ disinfection treatments, resulting in a considerably low release of PS during the contact with EtOH of less than $1 \mathrm{~min}$.

\section{Photostability of the embedded PS in the PU-coating}

Photobleaching is common in porphyrins like TPP, and can be slowed down by metal complexes or by the absence of oxygen. ${ }^{32}$ In our study, TPP-OH in PU was irradiated with the PIB 3000 lamp during the phototoxicity tests. In order to check a possible bleaching of TPP-OH by light excitation or by the photosensitized generation of ${ }^{1} \mathrm{O}_{2}$, the plates were irradiated under the same conditions without bacteria. The absorption spectra before and
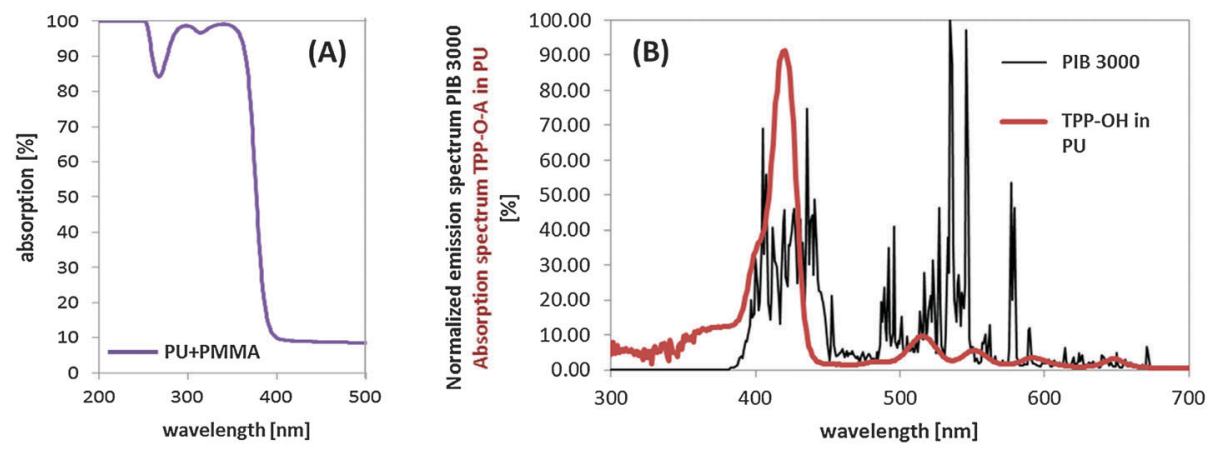

Fig. 4 (A) Absorption of the polymeric surface that consists of PMMA as basic material and a PU-coating of $\approx 30 \mu \mathrm{m}$; no PS is embedded in PU; (B) emission spectrum of the Waldmann PIB 3000 light source (black line; emission spectrum kindly provided by Waldmann Medizintechnik GmbH); the emission spectrum was normalized to its maximum; the absorption spectrum of TPP-OH doped into PU (TPP-OH concentration of $10^{-4}$ M; $\mathrm{PU}$ thickness of $\approx 30 \mu \mathrm{m}$ ) is shown in red and was determined by blank subtraction (blank: PMMA with PU-coating). 
after irradiation were measured and compared. The emission spectrum of PIB 3000 was normalized to its maximal value $(=100 \%)$ and overlaid with the absorption spectrum of TPP-OH $\left(10^{-4} \mathrm{M}\right)$ in PU (Fig. 4B) in order to estimate the irradiation effectivity. Irradiation of the samples between $5 \mathrm{~min}$ and $60 \mathrm{~min}$ $\left(E=15 \mathrm{~J} \mathrm{~cm}^{-2}\right.$ and $180 \mathrm{~J} \mathrm{~cm}^{-2}$ ) revealed no change of the absorption spectrum of TPP-OH within experimental accuracy. Due to the photostability under the herein tested conditions, the irradiation for $10 \mathrm{~s}$ with the laser in order to detect ${ }^{1} \mathrm{O}_{2}$ is considered as a neglectable energy application with regard to photostability.

\section{Detection of singlet oxygen generated by TPP-OH in the PU-coating}

The PU-surface doped with TPP-OH $\left(10^{-4} \mathrm{M}\right)$ was spectroscopically investigated in order to understand the process of the ${ }^{1} \mathrm{O}_{2}$ generation and decay in such a material. The ${ }^{1} \mathrm{O}_{2}$ detected luminescence was time-resolved and spectrally resolved in airsaturated samples at $25{ }^{\circ} \mathrm{C}$. The oxygen concentration of the surrounding air is $\left[\mathrm{O}_{2}\right]=8.54 \times 10^{-3} \mathrm{~mol} \mathrm{~L}^{-1}$. The $\mathrm{O}_{2}$ concentration in the PU-coating could not be determined for our samples. In general, diffusion seemed to play a critical role in PS quenching processes. Despite low diffusion coefficients in polymers, in comparison to air or liquid surrounding, oxygen diffusion into polystyrene with a diffusion constant of $D_{\mathrm{PS}}=$ $(2.3 \pm 0.2) \times 10^{-7} \mathrm{~cm}^{2} \mathrm{~s}^{-1}\left(25{ }^{\circ} \mathrm{C}, 1 \mathrm{~atm}\right)$ was reported by Poulsen et $a l .{ }^{33}$ In that study polymer films reached an equilibrium within $5 \mathrm{~s}$ after exposure of a degassed $10 \mu \mathrm{m}$ thick polystyrene film to oxygen. ${ }^{33}$ The time for reaching equilibrium of oxygen in the material should depend on the thickness of the polymer, and could be higher in our probe, exhibiting a PU-coating thickness of $\approx 30 \mu \mathrm{m}$.

The laser irradiation (10000 laser pulses, $\lambda=420 \mathrm{~nm}$ ) of TPP-OH $\left(10^{-4} \mathrm{M}\right)$ yielded a maximum of the integrated luminescence of ${ }^{1} \mathrm{O}_{2}$ at $1275 \mathrm{~nm}$ (Fig. 5A). In combination with a time-resolved measurement at $1270 \mathrm{~nm}$ (Fig. 5B), the generation of ${ }^{1} \mathrm{O}_{2}$ was directly proven $\left({ }^{1} \mathrm{O}_{2}\right.$ fingerprint $) .{ }^{34}$

Without knowing the oxygen concentration in the surface coating, it was nonetheless difficult to interpret the ${ }^{1} \mathrm{O}_{2}$ luminescence signals with regard to the assignment of rise and decay times to either the PS triplet state decay or the decay of ${ }^{1} \mathrm{O}_{2}$ to its ground state. ${ }^{35,36}$

The high intensity of the luminescence signal should enable a rather accurate determination of the rise and decay time of the signal applying the standard model and eqn (1). ${ }^{37,38}$ However, the detected luminescence signal offered more than one decay time that hampered the evaluation of the luminescence signal using eqn (1). The application of such a fit (Fig. 5B, red) resulted in a clear deviation from the measured data. The luminescence signal can be discussed as follows.

(i) The luminescence photons which are detected using the photomultiplier may originate from ${ }^{1} \mathrm{O}_{2}$ molecules decaying in different micro-environments like air bubbles in the PU-coating as shown by TEM imaging (Fig. 3B). Assuming a reasonably homogeneous PS distribution in the PU-coating, ${ }^{1} \mathrm{O}_{2}$ was homogeneously generated in PU-coating. With respect to a typical
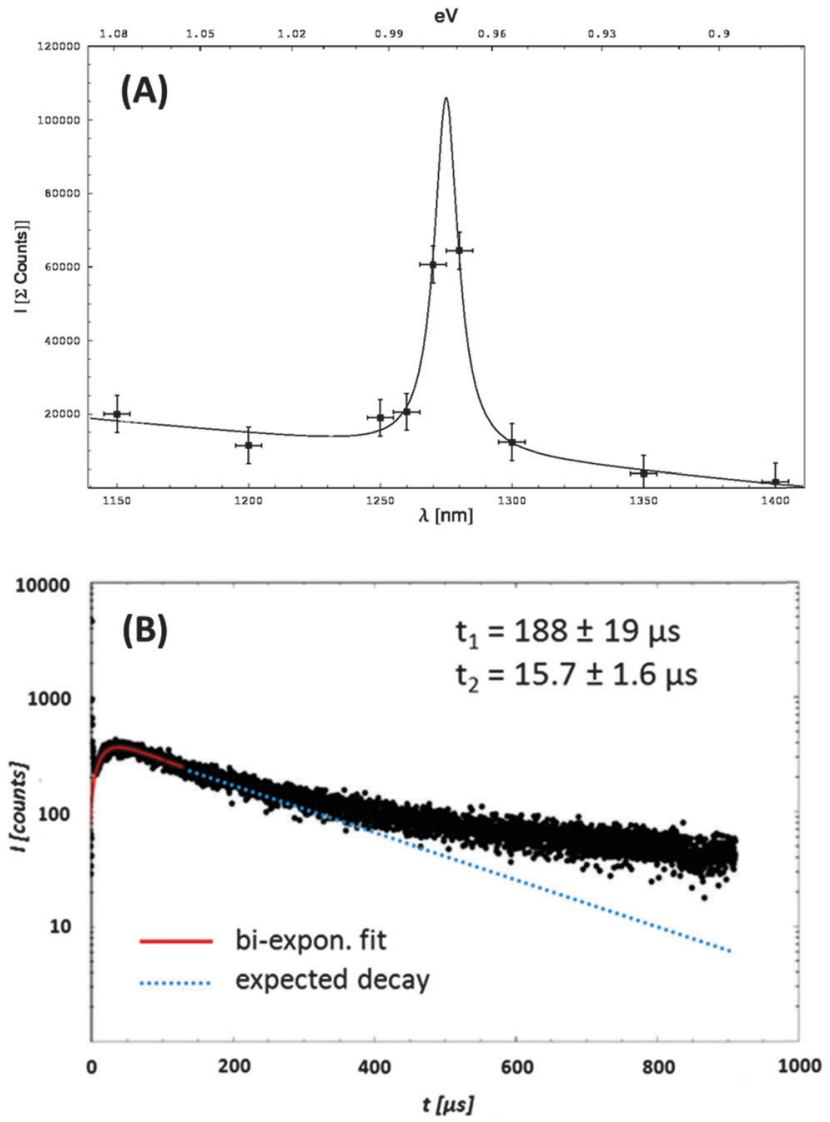

Fig. 5 (A) Spectrally resolved direct detection of ${ }^{1} \mathrm{O}_{2}$ generated by TPP$\mathrm{OH}$ in a PU-coating; TPP-OH has a concentration of $10^{-4} \mathrm{M}$; PU-coating thickness $\approx 30 \mu \mathrm{m}$; the samples were air-saturated at a temperature of $25{ }^{\circ} \mathrm{C}$; a Lorentz-function was fitted through the data points yielding a maximum at $1275 \mathrm{~nm}$. (B) Time-resolved direct detection of ${ }^{1} \mathrm{O}_{2}$ generated by TPP-OH in a PU-coating; TPP-OH has a concentration of $10^{-4} \mathrm{M}$; PUcoating thickness $\approx 30 \mu \mathrm{m}$; the respective rise and decay time, $t_{2}$ and $t_{1}$, were obtained by fitting the data (red solid line); deviation from the fitcurve is indicated by the blue dotted line.

diffusion constant of oxygen in polymer materials in the order of $\approx 10^{-7} \mathrm{~cm}^{2} \mathrm{~s}^{-1}$ and a ${ }^{1} \mathrm{O}_{2}$ lifetime of $\approx 100 \mu \mathrm{s}$, a diffusion length of ${ }^{1} \mathrm{O}_{2}$ of less than $100 \mathrm{~nm}$ was calculated. ${ }^{31,35,39}$

Dependence of the oxygen solubility on the free volume was shown by Boersma et al. on glassy polymers ${ }^{40}$ and might lead to multi-exponential decay manner of the detected luminescence signals of ${ }^{1} \mathrm{O}_{2}$ due to different sizes of free volume, like air bubbles. In contrast to that, Clough et al. state that ${ }^{1} \mathrm{O}_{2}$ itself has an intrinsic decay time within a polymer and thus exhibits first-order decay kinetics, whereas the excited triplet- $\mathrm{T}_{1}$-state decays in non-first-order kinetics. ${ }^{35}$

(ii) We investigated a new model by using a simpler approach (macroscopic model) that might help to understand the decay of ${ }^{1} \mathrm{O}_{2}$ measured. The PU-PMMA surface is an already complex system with the two different boundary layers, PMMA and air. ${ }^{1} \mathrm{O}_{2}$ was exclusively generated by TPP-OH in the PU-coating and can diffuse inside the PU-coating, into PMMA or into air to an unknown extent. Diffusion of ${ }^{1} \mathrm{O}_{2}$ molecules is terminated by collision with any other molecules in PMMA, PU-coating or air 
molecules which defines its decay. The shape of the ${ }^{1} \mathrm{O}_{2}$ luminescence signals confirmed this assumption showing different decay times, of which one part showed a fairly long decay time (see Fig. 5B). The decaying part finally disappears in the noise of the photomultiplier and its detection is further limited by the time resolution of the herein presented experimental setup. Although the whole decaying part cannot be resolved completely in time, its presence might affect the different decay times in PU, PMMA, and air by overlay of such different luminescence sources. Thus, the ${ }^{1} \mathrm{O}_{2}$ luminescence might be considered to be composed of spatially separated photon emission sources (PMMA, PU, air), each being more or less dominant and influencing to a certain extent rise and decay of the other luminescence signals generated at different sites.

To check the impact of ${ }^{1} \mathrm{O}_{2}$ diffusion on the luminescence signal, the diffusion of ${ }^{1} \mathrm{O}_{2}$ into surrounding air was almost inhibited by a sandwich-like structure (Fig. 6). Now, the TPP-OH containing PU-coating was attached on both sides of PMMA, exhibiting the same thickness compared to the original samples. Upon irradiation, ${ }^{1} \mathrm{O}_{2}$ was generated in the PU-coating and diffused inside PU, or escaped to PMMA. Due to the size of the sandwich polymer plate, the contact area of the PU-coating with surrounding air was $A_{\mathrm{PU} \text {-air }}=8 \times 10^{-2} \mathrm{~cm}^{2}$ and the contact area of PU with PMMA was $A_{\mathrm{PU} \text {-PMMA }}=32 \mathrm{~cm}^{2}$. Thus, the amount of ${ }^{1} \mathrm{O}_{2}$ molecules that still diffuses into air was considered negligible in the PU-sandwich structures. The sandwich polymer plate was irradiated as indicated by the arrow through the separate layers (Fig. 6). Assuming the same amount of $\mathrm{O}_{2}$ dissolved in the PU-coating of the sandwich-probes due to the same material properties, the deactivation of the excited PS triplet- $\mathrm{T}_{1}$-states should exhibit the same decay pattern compared to the original probes. However, the time-resolved luminescence signal was substantially changed.

First of all, the long decay time of the detected luminescence disappeared (Fig. 5 and 7) in the sandwich structure indicating

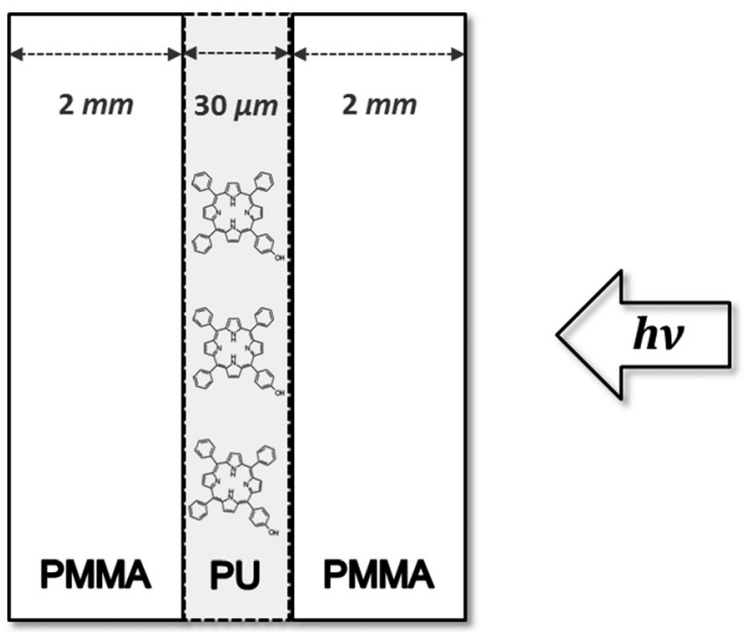

Fig. 6 Scheme of a "sandwich" polymer; the areas left and right indicate the PMMA material with a thickness of $2 \mathrm{~mm}$ each plate; the doped area in the middle shows the PU-coating $(\approx 30 \mu \mathrm{m})$ containing the polymerized PS TPP-OH; direction of irradiation is indicated by the arrow. that this signal correlated with ${ }^{1} \mathrm{O}_{2}$ decaying in air. We conclude that a part of the ${ }^{1} \mathrm{O}_{2}$ molecules diffused into air after excitation of the PU-coating (normal probes, PMMA coated with PU). This provides evidence that ${ }^{1} \mathrm{O}_{2}$ can escape the PU-coating and have the potential to kill microorganisms, which are located on that surface.

Surprisingly, the experiments with these sandwich structures showed a considerable shortening of both, rise and decay time of the ${ }^{1} \mathrm{O}_{2}$ luminescence (Fig. 7). At the moment, the shortening of both times is difficult to explain, in particular because the assignment of the rise and decay times of the luminescence signal to either the triplet $T_{1}$ state or singlet oxygen decay is not clear.

In the case of the surface coating system (Fig. 5), our detection system should have detected a superposition of luminescence signals that originate from three different environments, PMMA, $\mathrm{PU}$, and air. The photosensitizer is located in PU only and hence the photosensitizer triplet $\mathrm{T}_{1}$ state is quenched by oxygen in PU. After excitation in PU, singlet oxygen may diffuse into PMMA or air depending on the respective diffusion coefficient. Thus, we have the triplet $\mathrm{T}_{1}$ decay time of our photosensitizer in PU for given oxygen concentration in PU and potentially three different decay times of singlet oxygen molecules to a different extent in PU, PMMA, and air.

We assume that singlet oxygen can easily escape into air for our normal probes (PMMA coated with PU) due to the high diffusion coefficient of oxygen in air. In the case of the sandwich structure, diffusion of singlet oxygen is hampered by the second PMMA plate and singlet oxygen may remain in the PU layer for longer times. We tentatively assume that this may lead to more self-quenching of singlet oxygen by the photosensitizer that affects the decay time of singlet oxygen.

\section{Indirect detection of singlet oxygen by photodynamic killing and a chemical trap}

Phototoxicity experiments with these photodynamic active surfaces demonstrate the efficacy of the light induced generation of ROS like ${ }^{1} \mathrm{O}_{2}$ and their ability to kill microorganisms, depending on the irradiation time and the applied power. Herein, the phototoxicity effect was used as additional confirmation about ${ }^{1} \mathrm{O}_{2}$ which escaped the surface by diffusion. Additionally, ${ }^{1} \mathrm{O}_{2}$ diffusion was checked by using a chemical trap for ${ }^{1} \mathrm{O}_{2}$ (vide infra).

Therefore, the effective photodynamic killing of $S$. aureus applied on the PU-coating, which contained $1 \times 10^{-4} \mathrm{M}$ or $2 \times 10^{-4} \mathrm{M}$ of TPP-OH, was investigated. After applying $S$. aureus onto the PU surface, the area of interest was irradiated consequently. Therefore, two different irradiation times $(10 \mathrm{~min}$, $30 \mathrm{~min}$ ) were used with a constant intensity of $50 \mathrm{~mW} \mathrm{~cm} \mathrm{~cm}^{-2}$ (Waldmann PIB 3000). For each condition, dark and light controls were monitored, using the dark control (PU without PS) as reference.

First the recovery efficiency was measured to determine the range of viable $S$. aureus applied on the surface after the drying process. A loss of only $20 \%$ of $S$. aureus $\left(\approx 0.1 \log _{10}\right.$ steps) was counted after the swabbing procedure when compared to the initial number of bacteria in suspension (data not provided). 

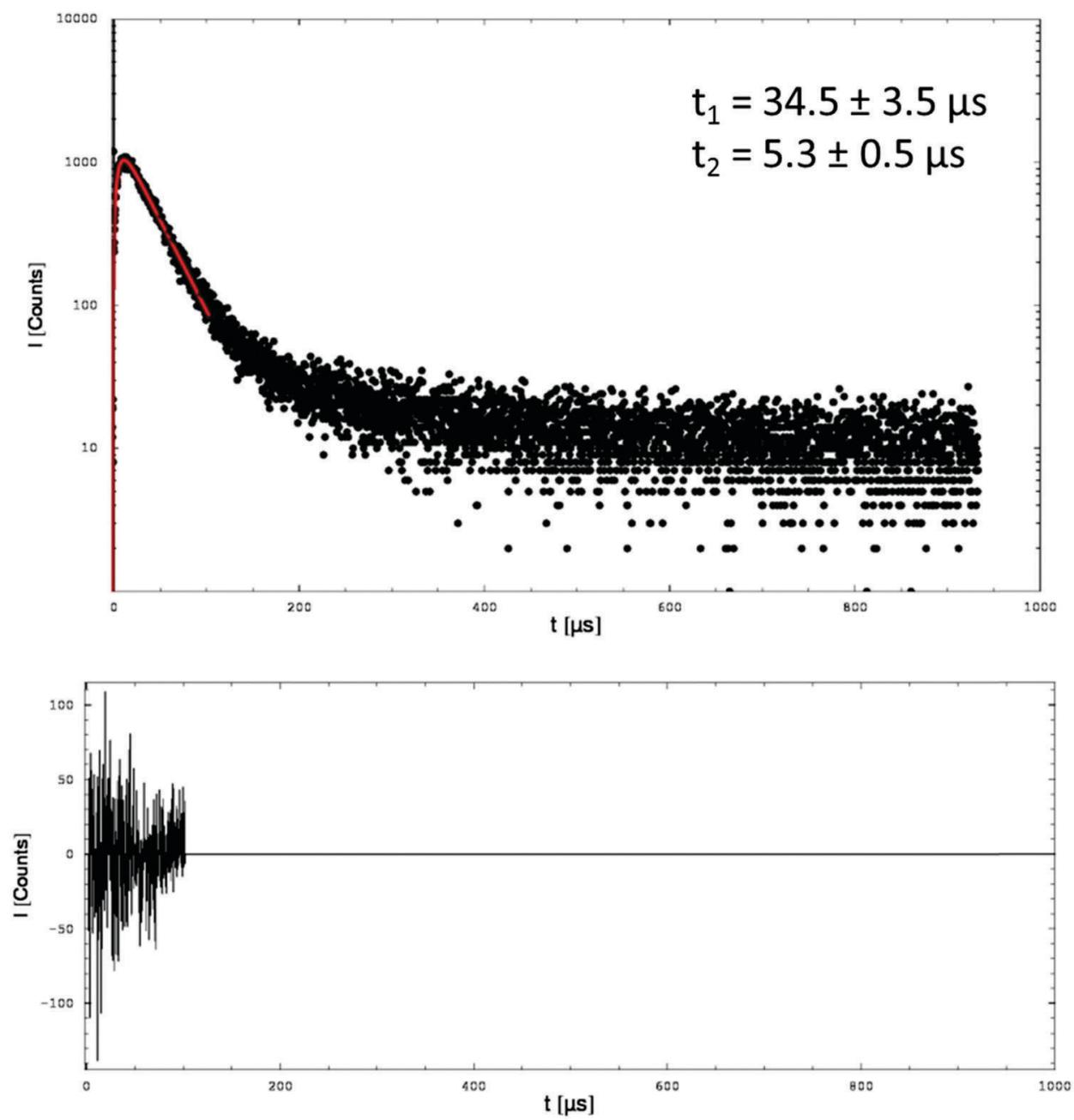

Fig. 7 Time-resolved direct detection of ${ }^{1} \mathrm{O}_{2}$ generated by TPP-OH in a PU sandwich polymer with a concentration of $10^{-4} \mathrm{M}$ and a PU-coating thickness of $30 \mu \mathrm{m}$; the samples were air saturated at a temperature of $25^{\circ} \mathrm{C}$. $t_{1}$ and $t_{2}$ were obtained by a bi-exponential fit in the first part of the luminescence signal; the deviation of the fit-curve is shown below the ${ }^{1} \mathrm{O}_{2}$ luminescence signal and an increased deviation can be followed with increasing time.

This resulted in a reproducible correlation between the used swabbing method and the recovery efficiency. The herein presented S. aureus recovery data are in line with previously published results on a porcine skin model using the same bacteria species and applying three swabbing steps. ${ }^{41}$ Furthermore, no dark toxicity towards $S$. aureus was detected on the PU-coating.

Irradiation of TPP-OH in the PU-coating for $10 \mathrm{~min}$ and $50 \mathrm{~mW} \mathrm{~cm}{ }^{-2}$ did not exhibit noteworthy killing effects against $S$. aureus within the experimental accuracy of $0.5 \log _{10}$-steps (data not provided). However, Fig. 8 shows the reduction of applied $S$. aureus for the irradiation time of $30 \mathrm{~min}$. A phototoxic effect was clearly demonstrated on the PU surface containing TPP-OH. The killing efficacy of $0.7 \log _{10}$-steps $(80 \%)$ with a PS concentration of $10^{-4} \mathrm{M}$ was determined, but is not considered biologically relevant. However, a concentration of $2 \times 10^{-4} \mathrm{M}$ yielded a reduction of $3.2 \log _{10}$-steps (99.937\%). Irradiation of $30 \mathrm{~min}$ of PU-samples without TPP-OH (light control) resulted in a reduction of $0.3 \log _{10}$-steps (50\%) which is considered as no effect within experimental accuracy. This study clearly demonstrated a dependency of the killing efficacy on the PS concentration and the irradiation time. The photodynamic killing efficacy is comparable to already reported efficacies. ${ }^{42-44}$ In our study strict exclusion of PS leakage in the aqueous surrounding was confirmed.

It has to be noted that the herein presented phototoxicity experiments were not the main issue of this study, but supported the conclusion based on the luminescence experiments that ${ }^{1} \mathrm{O}_{2}$ diffuses from the surface material into air leading to oxidative damage of bacteria. A study will be conducted in the near future to optimize the light source and the applied PS, which should be photostable for long times and consistently generate ${ }^{1} \mathrm{O}_{2}$ to a high extent.

In order to investigate ${ }^{1} \mathrm{O}_{2}$ diffusion into air using an indirect method, a chemical trap of ${ }^{1} \mathrm{O}_{2}$ was applied. A reaction with a solution of potassium iodide leads to the formation of tri-iodide which can be detected via absorption spectroscopy. This reaction can be used to detect the presence of ${ }^{1} \mathrm{O}_{2}$ and 


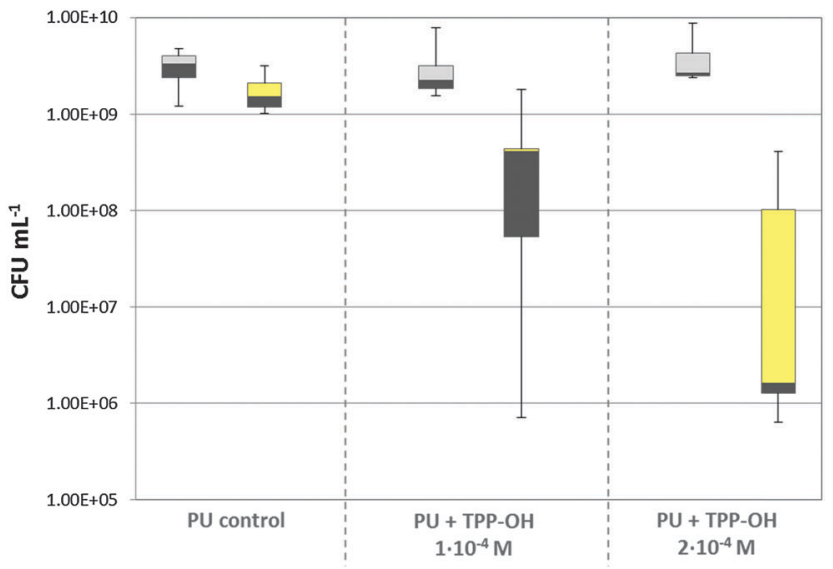

Fig. 8 Box-and-whisker plot of the photodynamic treatment of S. aureus on photoactive polymer surfaces in numbers of $\mathrm{CFU} \mathrm{mL} \mathrm{L}^{-1}$; irradiation of $\mathrm{PU}$ without PS (control) and PU containing TPP-OH in concentrations of $10^{-4} \mathrm{M}$ or $2 \times 10^{-4} \mathrm{M}$ (irradiation time $=30 \mathrm{~min}, P=50 \mathrm{~mW} \mathrm{~cm}{ }^{-2}$ ); each column has a pair of boxes of which the left characterises the CFU mL ${ }^{-1}$ of the dark control and the right the CFU mL ${ }^{-1}$ after light treatment; maximum/ minimum values, $25 \%$ (grey) and $75 \%$ (yellow) percentiles and median are displayed; median of the dark control for each condition was used as reference for calculating the $\log _{10}$-reduction by comparison with the median of the light treated probe.

allows its quantification. This method, however, is also sensitive for $\mathrm{H}_{2} \mathrm{O}_{2}$, as can be seen from the reaction scheme (vide supra). ${ }^{25,28}$

For increasing irradiation time (light dose up to $90 \mathrm{~J} \mathrm{~cm}^{-2}$ ) the formation of tri-iodide was detected by monitoring the typical maxima of the absorption intensity for tri-iodide at $287 \mathrm{~nm}$ and $350.5 \mathrm{~nm}$ (Fig. 9). The Fig. 9 inset shows a linear correlation between the applied light dose and the total percentage of absorption at $350.5 \mathrm{~nm}$. In our measurements also the irradiation of PU-coating on PMMA without PS led to the

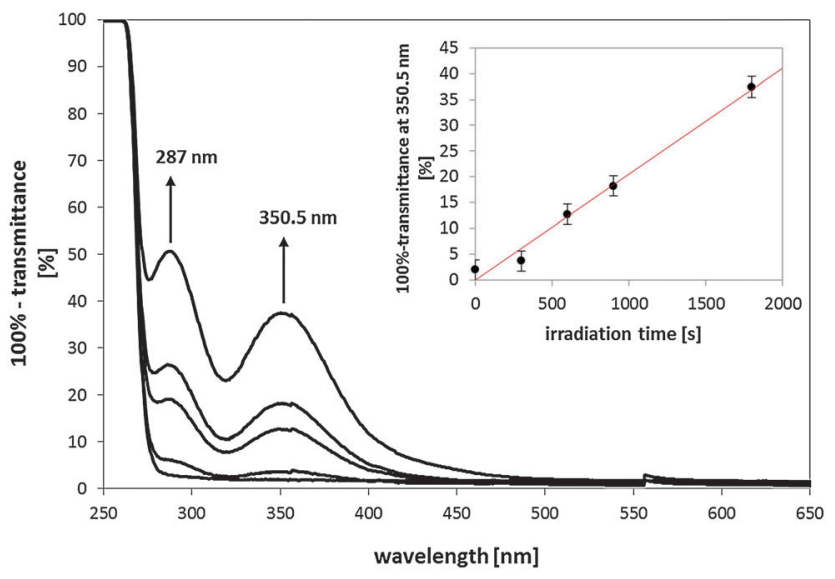

Fig. 9 Dependency of the absorption of tri-iodide on the irradiation time of TPP-OH with a concentration of $10^{-4} \mathrm{M}$ linked in PU-coating (thickness $\approx 30 \mu \mathrm{m})$; the probes were irradiated with $0,15,30,45$, and $90 \mathrm{~J} \mathrm{~cm}^{-2}$ using the Waldmann PIB $3000\left(P=50 \mathrm{~mW} \mathrm{~cm}^{-2}\right.$ at the level of the samples); the concentration of potassium iodide in $\mathrm{H}_{2} \mathrm{O}$ was $120 \mathrm{mM}$; (inset) absorption of tri-iodide recorded at $350.5 \mathrm{~nm}$ in dependency of the irradiation time (errors: $\Delta y=2 \%, \Delta x=2$ s). formation of tri-iodide, though to a much lower extent. Since ${ }^{1} \mathrm{O}_{2}$ generation in these probes was not detected with the direct spectroscopic method, we consider an additional ROS has been formed during irradiation. EPR-detection already showed that the irradiation of PU generated $\mathrm{H}_{2} \mathrm{O}_{2}$ that additionally offers materials with long-lasting antibacterial properties. ${ }^{31}$ In our case, the presence of another ROS clearly impeded the detection of ${ }^{1} \mathrm{O}_{2}$ diffusion into air with the used indirect methods. Therefore, ${ }^{1} \mathrm{O}_{2}$ or $\mathrm{H}_{2} \mathrm{O}_{2}$ quenchers and ROS scavengers will be used in future experiments to exclude certain reaction pathways and give a clear evidence of the involved reactive species.

\section{Conclusions}

In a polymeric surface based on the polyurethane material ${ }^{20}$ the ${ }^{1} \mathrm{O}_{2}$ luminescence signal exhibited a multi-exponential decay which might be due to a deactivation in different surroundings like PU, PMMA, and the surrounding air. Simplifying the samples by the inhibition of ${ }^{1} \mathrm{O}_{2}$ diffusion into the surrounding air shortened the rise and especially the decaying part of the luminescence to a great extent and might help to elucidate the different deactivation paths.

That diffusion was confirmed by using indirect methods, like bacteria killing and the formation of tri-iodide. However, the light assisted generation of other ROS on the surface of the PU-coating cannot be ruled out. The determination of the reduction of bacteria on the surface is a clear proof of the generation of ${ }^{1} \mathrm{O}_{2}$ and other ROS that are able to escape the surface. We showed that photokilling of $S$. aureus on the surface with an efficiency of $>99.9 \%$ was possible with the given properties. The photokilling effectiveness of the PU-coated surfaces depended on the irradiation time and the concentration of the PS.

The first results of the present photoactive surfaces are promising, and therefore it is an important goal for the near future to optimize the photodynamic effect by selection of a PS with a sufficient ${ }^{1} \mathrm{O}_{2}$ generation, the optimal PS concentration, irradiation time, and irradiation power. Reports on bacterial cell numbers on surface hospitals reveal a rather low number of colony forming units (CFU) per area. Rutala et al. mention bacterial densities between 4-7 CFU $\mathrm{cm}^{-2}$, encountered on hospital surfaces of rooms occupied by patients with $S$. aureus infections. ${ }^{45}$ Since microorganism photokilling on the surface is a continuous procedure, depending on light availability, it is worth mentioning that the definition of killing efficacy should be reconsidered and redefined and might not be compared to the method of photokilling in solution.

\section{Acknowledgements}

The authors thank the company Warnecke \& Böhm for the coating of the surfaces, Heiko Siegmund of the Central EM Lab of the University Hospital Regensburg for the electron microscopic examination, and Micaela Antonini for her technical assistance in the phototoxicity experiments. This project was 
supported by ZIM KF2525602CS1 (Zentrales Innovationsprogramm Mittelstand, Germany).

\section{References}

1 V. Decraene, D. Ready, J. Pratten and M. Wilson, J. Gen. Appl. Microbiol., 2008, 54, 195-203.

2 A. Kramer, I. Schwebke and G. Kampf, BMC Infect. Dis., 2006, 6, 130.

3 K. Page, M. Wilson and I. P. Parkin, J. Mater. Chem., 2009, 19, 3819-3831.

4 D. Campoccia, L. Montanaro and C. R. Arciola, Biomaterials, 2013, 34, 8533-8554.

5 A. Taglietti, C. R. Arciola, A. D’Agostino, G. Dacarro, L. Montanaro, D. Campoccia, L. Cucca, M. Vercellino, A. Poggi, P. Pallavicini and L. Visai, Biomaterials, 2014, 35, 1779-1788.

6 F. Baquero, M. C. Negri, M. I. Morosini and J. Blazquez, Clin. Infect. Dis., 1998, 27, S5-S11.

7 M. J. Niedre, A. J. Secord, M. S. Patterson and B. C. Wilson, Cancer Res., 2003, 63, 7986-7994.

8 X. Ragas, L. P. Cooper, J. H. White, S. Nonell and C. Flors, ChemPhysChem, 2011, 12, 161-165.

9 X. Ragas, M. Agut and S. Nonell, Free Radical Biol. Med., 2010, 49, 770-776.

10 T. A. Dahl, W. R. Midden and P. E. Hartman, Photochem. Photobiol., 1987, 46, 345-352.

11 W. R. Midden and S. Y. Wang, J. Am. Chem. Soc., 1983, 105, 4129-4135.

12 V. Decraene, J. Pratten and M. Wilson, Curr. Microbiol., 2008, 57, 269-273.

13 V. Decraene, J. Pratten and M. Wilson, Infection Control and Hospital Epidemiology, 2008, 29, 1181-1184.

14 S. Ismail, S. Perni, J. Pratten, I. Parkin and M. Wilson, Infection Control and Hospital Epidemiology, 2011, 32, 1130-1132.

15 M. Wilson, Infection Control and Hospital Epidemiology, 2003, 24, 782-784.

16 J. Wahlen, D. E. De Vos, P. A. Jacobs and P. L. Alsters, Adv. Synth. Catal., 2004, 346, 152-164.

17 R. W. Redmond and J. N. Gamlin, Photochem. Photobiol., 1999, 70, 391-475.

18 J. Mosinger and B. Mosinger, Experientia, 1995, 51, 106-109.

19 P. Osswald, C. C. You, V. Stepanenko and F. Wurthner, Chem. - Eur. J., 2010, 16, 2386-2390.

20 B. Bisdorff, J. L. Scholholter, K. Claussen, M. Pulz, D. Nowak and K. Radon, Epidemiol. Infect., 2012, 140, 1800-1808.

21 A. A. Miles, S. S. Misra and J. O. Irwin, J. Hyg., 1938, 38, 732-749.

22 J. M. Boyce and D. Pittet, Infection Control and Hospital Epidemiology, 2002, 23, S3-40.

23 J. G. Parker and W. D. Stanbro, Prog. Clin. Biol. Res., 1984, 170, 259-284.
24 J. Baier, T. Fuss, C. Pollmann, C. Wiesmann, K. Pindl, R. Engl, D. Baumer, M. Maier, M. Landthaler and W. Baumler, J. Photochem. Photobiol., B, 2007, 87, 163-173.

25 J. Mosinger, M. Janoskova, K. Lang and P. Kubat, J. Photochem. Photobiol., A, 2006, 181, 283-289.

26 A. Felgentrager, F. P. Gonzales, T. Maisch and W. Baumler, J. Biomed. Opt., 2013, 18, 045002.

27 C. Brückner, J. R. McCarthy, H. W. Daniell, Z. D. Pendon, R. P. Ilagan, T. M. Francis, L. Ren, R. R. Birge and H. A. Frank, Chem. Phys., 2003, 294, 285-303.

28 M. Korinek, R. Dedic, A. Svoboda and J. Hala, J. Fluoresc., 2004, 14, 71-74.

29 R. F. Pasterna, G. C. Centuro, P. Boyd, L. D. Hinds, P. R. Huber, L. Francesc, P. Fasella, G. Engasser and E. Gibbs, J. Am. Chem. Soc., 1972, 94, 4511-4517.

30 E. Zenkevich, E. Sagun, V. Knyukshto, A. Shulga, A. Mironov, O. Efremova, R. Bonnett, S. P. Songca and M. Kassem, J. Photochem. Photobiol., B, 1996, 33, 171-180.

31 S. Jesenska, L. Plistil, P. Kubat, K. Lang, L. Brozova, S. Popelka, L. Szatmary and J. Mosinger, J. Biomed. Mater. Res., Part A, 2011, 99A, 676-683.

32 J. A. S. Cavaleiro, H. Gorner, P. S. S. Lacerda, J. G. MacDonald, G. Mark, M. G. P. M. S. Neves, R. S. Nohr, H. P. Schuchmann, C. van Sonntag and A. C. Tome, J. Photochem. Photobiol., A, 2001, 144, 131-140.

33 L. Poulsen, I. Zebger, P. Tofte, M. Klinger, O. Hassager and P. R. Ogilby, J. Phys. Chem. B, 2003, 107, 13885-13891.

34 A. Eichner, F. P. Gonzales, A. Felgentrager, J. Regensburger, T. Holzmann, W. Schneider-Brachert, W. Baumler and T. Maisch, Photochem. Photobiol. Sci., 2013, 12, 135-147.

35 R. L. Clough, M. P. Dillon, K. K. Iu and P. R. Ogilby, Macromolecules, 1989, 22, 3620-3628.

36 X. Lu and M. A. Winnik, Chem. Mater., 2001, 13, 3449-3463. 37 J. G. Parker and W. D. Stanbro, J. Photochem., 1984, 25, 545-547.

38 J. Baier, T. Fuss, C. Pollmann, C. Wiesmann, K. Pindl, R. Engl, D. Baumer, M. Maier, M. Landthaler and W. Baumler, J. Photochem. Photobiol., B, 2007, 87, 163-173.

39 A. Wolinska-Grabczyk and A. Jankowski, Sep. Purif. Technol., 2007, 57, 413-417.

40 A. Boersma, D. Cangialosi and S. J. Picken, Polymer, 2003, 44, 2463-2471.

41 T. Maisch, C. Bosl, R. M. Szeimies, B. Love and C. Abels, Photochem. Photobiol. Sci., 2007, 6, 545-551.

42 V. Decraene, J. Pratten and M. Wilson, Appl. Environ. Microbiol., 2006, 72, 4436-4439.

43 R. Bonnett, M. A. Krysteva, I. G. Lalov and S. V. Artarsky, Water Res., 2006, 40, 1269-1275.

44 M. D. Funes, D. A. Caminos, M. G. Alvarez, F. Fungo, L. A. Otero and E. N. Durantini, Environ. Sci. Technol., 2009, 43, 902-908.

45 W. A. Rutala, E. B. Katz, R. J. Sherertz and F. A. Sarubbi Jr., J. Clin. Microbiol., 1983, 18, 683-688. 